\title{
Presentation of the Howland Award, May, 1983
}

\author{
LAURENCE FINBERG
}

Department of Pediatrics, State University of New York, Downstate Medical Center, Brooklyn, New York, USA

Three special features characterize the thirty-second award of the Howland Medal. The first is unique in that the award is to a team of pediatric investigators, a married couple, Helen C. and Harold E. Harrison. Second, more than in most years of honoring the distinguished men and women of pediatrics, this one clearly illuminates the strong generational ties and continuity in American pediatrics during the 78 years since John Howland became a member of the American Pediatric Society. Finally, this year's award recognizes excellence across the whole spectrum of pediatrics specified in our constitution: advancement of knowledge, education, clinical treatment and prevention of children's diseases, and also humanitarian child advocacy.

Helen Coplan Harrison was born and had her early education in Baltimore, Maryland, graduating from Goucher College with an A.B. in biology at age 20 . She continued her education while teaching at Goucher and working summers at the Woods Hole Marine Biological Laboratory. She then went on to receive a Masters Degree from Smith College and entered a doctorate program at Yale under the tutelage of C. N. H. Long, the Chairman of what was then called the Department of Physiological Chemistry. Following Long's interests she worked in the field of adrenal physiology and biochemistry. She met and was intellectually stimulated by the scientific giants at the Yale Medical School and she also met a young chief resident in pediatrics who shared some of her scientific and, soon thereafter, other interests. We have a picture of her at the time taken by Dr. Long (Fig. 1).

Harold E. Harrison was born in New Haven, Connecticut and had all of his formal education there including a B.S. in chemistry and an M.D. from Yale by the time he was 23. His career was strongly influenced, while a second year student in medical school, by hearing a lecture given by John P. Peters on acid/base equilibrium. As many a student has since, this very bright young chemist found the material confusing, leading him to want to know more about electrolytes. Yale students were required to do a thesis; he decided to do his involving electrolytes on a project he proposed to do in Peters' laboratory. After applying, he was told by Peters to come back with a specific proposal for research. He determined his project and had it accepted after reading a paper by James L. Gamble (Fourth Howland Medalist), on external balance studies of electrolytes. This was the start of many years of productive work in this field. By the following year while doing a clinical clerkship he first admired, and then came under the influence of that master clinician and humanitarian, Grover F. Powers (second Howland Medalist). He decided then on a career in Pediatrics. It was very easy to combine his research interest with his clinical choice because Daniel C. Darrow (eighth Howland Medalist) was actively working in this field.

These two men, Powers and Darrow, served as his mentors directly for the next 10 years of his life, and though from a distance, for much longer. From Powers one can trace the acquisition of his great bedside clinical gifts, his empathy for sick children and their parents, and his posture of advocacy for children. From Darrow came enhancement of his own precocious scientific skills, a breadth of approach to science, and, perseverence to do whatever task correctly and elegantly. From both of them came the example of rigorous unbending integrity, openness of mind, and freedom from intolerance to people or ideas. Both of these preceptors had the pleasure of seeing their skills and attitudes adopted, and merged with Harold's native abilities as he flourished.

When our medalist graduated from medical school he became an intern in Pediatrics. He can be seen in the picture (Fig. 2) as can Dr. Powers. After two years of residency he was offered a fellowship permitting him to stay in the department. Before starting his work in Darrow's Laboratory he visited Gamble who advised him that the proposed association was an outstanding one, and so it proved to be. The following year he was back on the wards as a chief resident and had begun to court Helen. When a patient with unexplained glycosuria-clearly not diabetes-appeared, he had a friend who had access to a polarizing microscope. This instrument, set up in a small closet of a room, enabled him to astound the faculty with proof of fructosuria on morning rounds. What else happened in the closet is not recorded but surely was also exhilarating.

In 1936 our two medalists were married looking as shown in the picture (Fig. 3). Two more pictures (Fig. 4 and 5) from this era show the Pediatric Department of Yale in 1936 and the Physiological Chemistry Department in 1937. From this point forward their careers were joined but not yet their scientific work. Harold was now working full time with Darrow. Five papers coauthored by them appeared over the next three years. This work was seminal in defining the distribution of water and electrolytes in body spaces. One of these papers contributed a method for the volumetric determination of potassium in body fluids. The flame photometer was not yet invented. Toward the end of this period Helen and Harold published their first paper together. Not surprisingly it involved studies of electrolytes, carbodhydrate, and an adrenal hormone.

It was time to leave New Haven and our couple went to New York to Samuel Levine's (Thirteenth Howland Medalist) Department at Cornell. They stayed four years at New York Hospital where, at the time internists sometimes made Sunday rounds in morning coat and striped trousers. They renewed their earlier friendship and collaborated with Harry Gordon (Twentyfourth Howland Medalist) who had earlier been a pediatric resident at Yale.

At this time they began an interest in phosphate excretion that was to start them down a new research road. They also demonstrated in the laboratory, with specimens from adult patients, that chronic diarrhea results in a deficiency of body potassium. Harold developed a method for inulin determination in order that Helen McNamera then working for Harry Gordon wouldn't have corks popping against the wall between their laboratories. This had happened because of a flaw in the old method. Aside from its scientific importance, this could also be looked upon as a contribution to noise abatement.

World War II caused them to relocate. Although Harold had enlisted in the Army, he found his orders changed by his former Dean at Yale, Dr. Milton Winternitz, who needed him as the physiologist to a chemical warfare project. They thus returned to New Haven, but not before jointly receiving the E. Mead Johnson Award for Pediatric Research of the American Academy of Pediatrics. 
By the time the war had ended their first son Stephen was born and what proved to be their second was gestating. The phosphate paper mentioned earlier plus their reputation for general excellence had caught the eye of Dr. Edwards A. Park (The First Howland Medalist). Dr. Park, an early associate of Howland was then nearing the end of his long and extended (by war) chairmanship of Pediatrics at the Johns Hopkins School of Medicine. He had also an abiding interest in rickets, particularly its pathology. He planned to continue this interest in what ultimately proved to be an active 23 years of "retirement." He recognized from the literature and through conversation that the Harrisons had a lively and sophisticated interest in calcium and

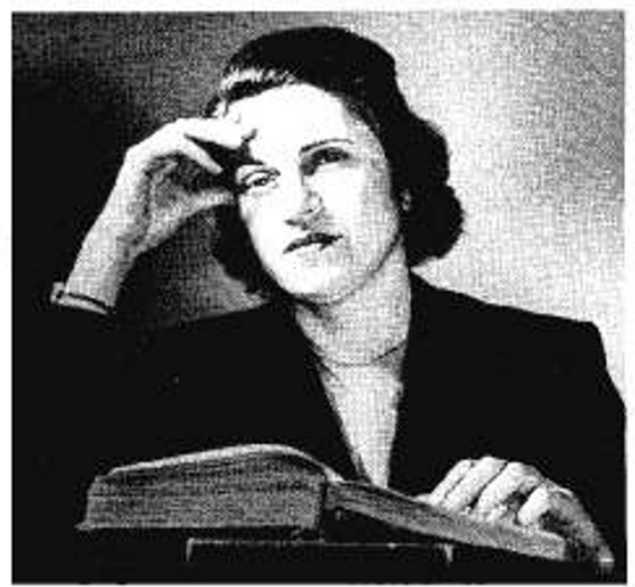

Fig. 1. Helen Harrison while a Graduate Student.

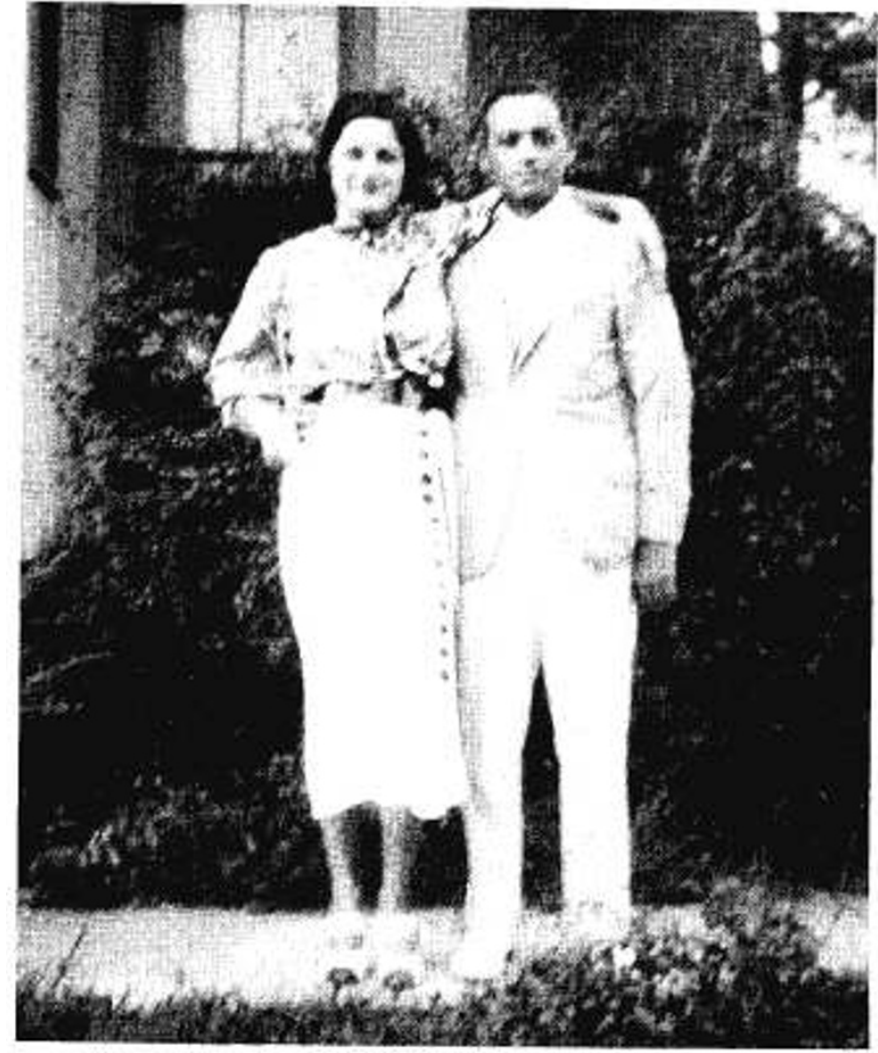

Fig. 3. Newly married.

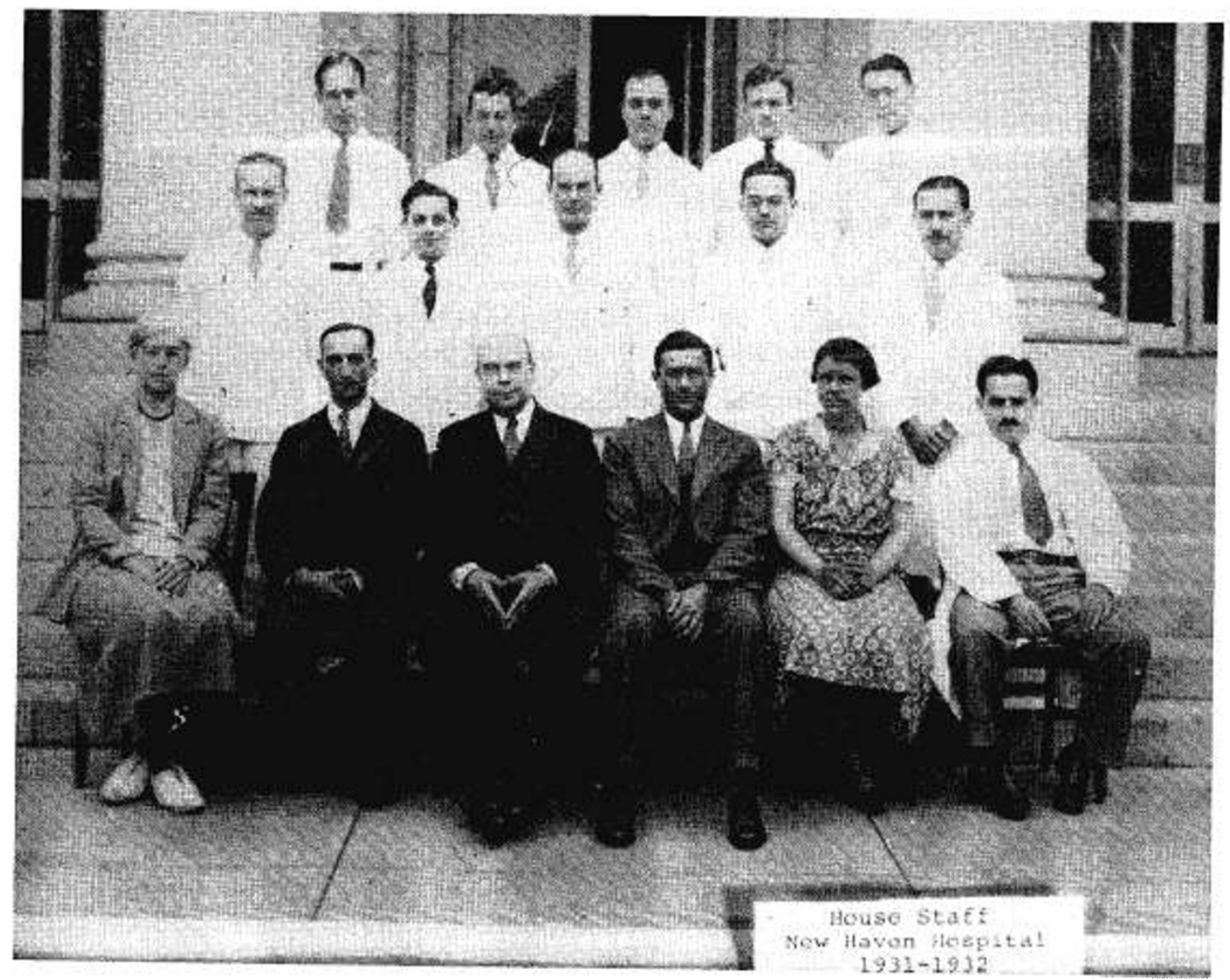

Fig. 2. Pediatric House Staff Picture, Yale New Haven Hospital, 1931-32. Dr. Powers is 3rd from left, first row, seated. Dr. Harrison is $2 \mathrm{nd}$ from left, first row, standing. 


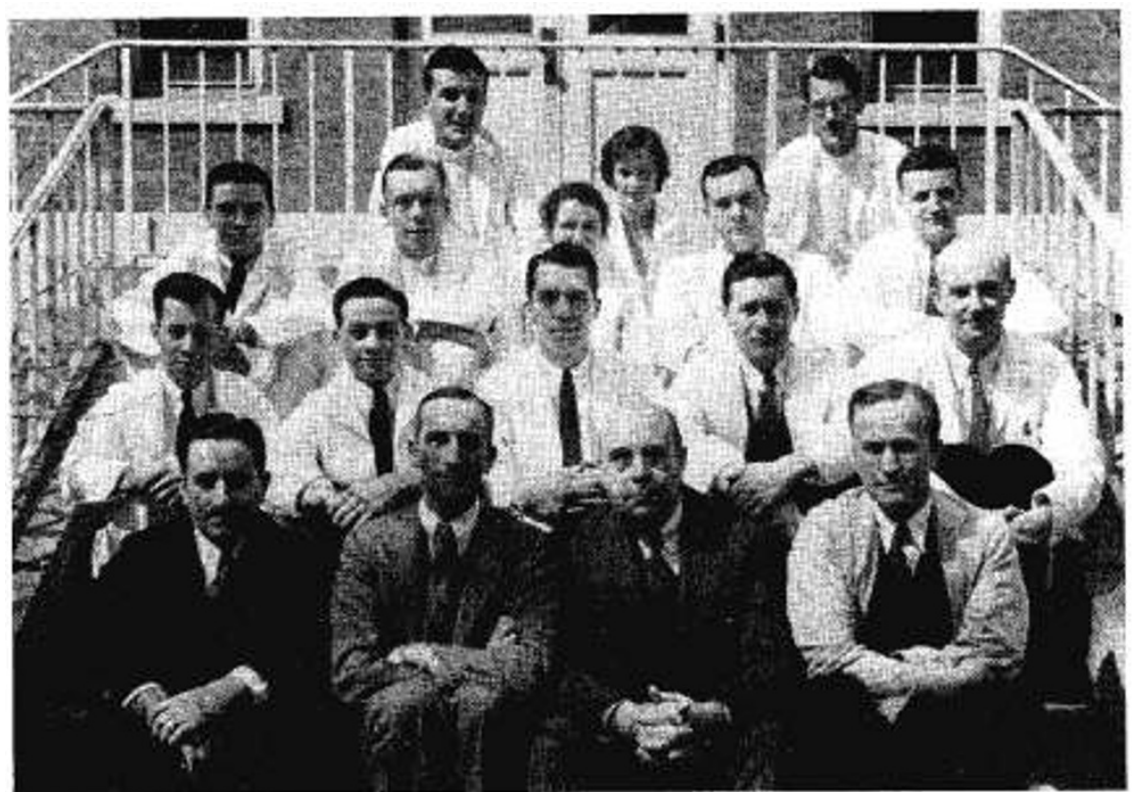

Fig. 4. Yale/New Haven Hospital, Pediatric Staff picture, May, 1956. First row: Charles Culotta, James D. Trask, Grover F. Powers, and Daniel C. Darrow, second row: Ralph A. Ross, Harold E. Harrison, Myron E. Wegman, Herman Yannet, and Frank Martin, third row: Conrad Baker, John A. Lichty, Elizabeth Chittenden, Thomas A. Shaffer, and Herbert C. Miller, and back row: M. Leo Furcolow, Agnes Beeber, and Clark Searle.

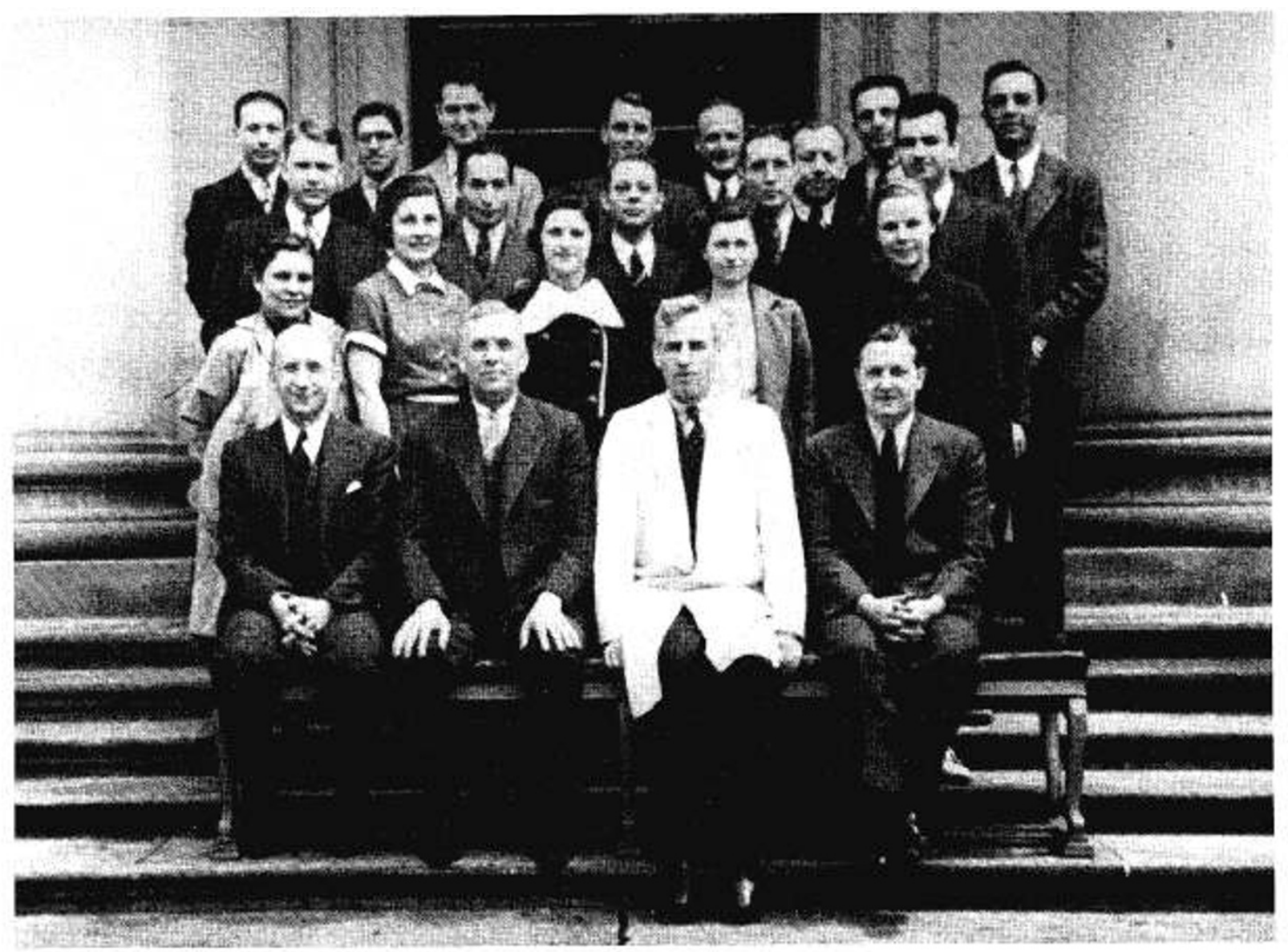

Fig. 5. Department of Physiological Chemistry, Yale, 1937. Graduate Student Helen C. Harrison 3rd from left, first standing row.

phosphorous metabolism. Therefore he determined to lure them to Baltimore so that they might collaborate and extend the work on rickets. Park, not being sure of what his successor would want in the Hopkins Department, arranged a hospital appointment for Harold as Chief of Pediatrics at the Baltimore City Hospitals in 1945 . He also secured access to a laboratory at the Harriet
Lane Home for them. A few months after arrival Richard was born. Helen busy with two infants did not return to the laboratory for a year or so.

The summer of 1945 was important to this chronology in another way. Darrow had become interested in applying his concept of the therapeutic value of parenteral potassium to 
dehydrated infants. Summer diarrhea was no longer a major problem in New Haven and carrying out collaborative work in Texas was complicated. Diarrheal disease became prevalent in Baltimore that summer and the patients were not doing well. Park invited Darrow to come, organize the therapeutic program and conduct his research. He did and a major milestone in medicine was achieved; quickly recognized by surgeons and internists as well as pediatricians. A by-product of this work was a discussion between Darrow and today's medalist about the oral administration of electrolytes. From this conversation, Baltimore and New Haven became trial sites for the first scientifically formulated oral glucose-electrolyte solutions (Fig. 6). This seemed so simple and automatic to them that little was published, necessitating rediscovery 25 years later.

At this point a brief review of the 1946 Baltimore City Hospitals Pediatric Service is in order. First the hospital itself, in many ways similar to other city/county hospitals around the country had not kept up with the changes in medicine. There were, in 1946, about 2000 patients on the grounds, 450 of them in the "acute" hospital. For these patients all of the technical procedures in clinical chemistry, microbiology, hematology, and electrocardiography was performed by two untrained technicians. There was no Social Service Department, and in Pediatrics no outpatient department other than the emergency room. There had been a prior pediatric training program, but it had atrophied

$$
\begin{aligned}
& \text { Baltimore City Hospitals (BCH) 非 } \\
& \begin{array}{lr}
\text { (a liquid) } \\
\mathrm{Na} & -62 \mathrm{mEq} / 1 \\
\mathrm{~K} & -20 \mathrm{mEq} / 1 \\
\mathrm{Cl} & -52 \mathrm{mEq} / 1 \\
\text { Lactate } & -30 \mathrm{mEq} / 1 \\
\text { Glucose } & -33 \mathrm{gm} / 1
\end{array}
\end{aligned}
$$

Fig. 6. Composition of first glucose/electrolyte solution, "Special Rx", used at the Baltimore City Hospitals. during the war, so that there were no house officers on board as Harold started in 1946. He made rapid strides, emphasizing quality and excellence in care and gradually in staff. It was still a small group in 1950 (Fig. 7) and a bit larger in 1952 (Fig. 8). What Harold was offering was personal interest, great breadth of knowledge, dedication and high standards of conduct and of service to offset the handicaps then largely inherent in municipal hospitals.

Early in his stay at Baltimore City Hospitals, along with a bright able chief resident, Julius Ennis, Harold used his war years experience with BAL to introduce that compound into the therapy of the then (and even now) scourge of inner city children, lead poisoning. This was an important advance. He also began a campaign to remove the old slum housing which caused most of the problems. Later Julian Chisolm was to take up these efforts.

For 3 years, the Harrisons took no vacation while he made ward rounds 6 days a week, started a premature infant nursery, organized an OPD, and recruited staff while remaining fruitful in the laboratory. The last was possible because Helen ran the laboratory. The Harrisons had many ideas concerning human biology; Dr. Park's insistent presence and cajoling insured that calcium metabolism was a main focus.

The level of clinical care given to patients at $\mathrm{BCH}$, patients generally not wanted elsewhere in Baltimore, rivaled that anywhere in the world. Powers' protege not only excelled but brought science to the bedside of those children and their illnesses as perhaps had not happened before. Certainly nowhere was care better. The teaching of residents by example and through articulate discussion was also extraordinary. Although an expert in several particular areas of pediatric knowledge, he was always also the epitome of the pediatric general clinician. Virtually all clinical problems fell within his broad range of knowledge and unrivaled clinical competence. When, on uncommon occasions, he needed help it was immediately acknowledged and promptly sought. No ego, his or that of a staff member, was stroked at the even momentary expense of a patient. The new Pediatric Clinical Chemistry Laboratory, thanks in part to the talent of a superb technician, Evelyn Fleischman, may have been the best anywhere, and certainly decades ahead of its time.

The Harrisons' laboratory at the Harriet Lane Home produced data and publications on citrate metabolism, on the effects of azetozolemide on the kidney, on phosphate transport in the

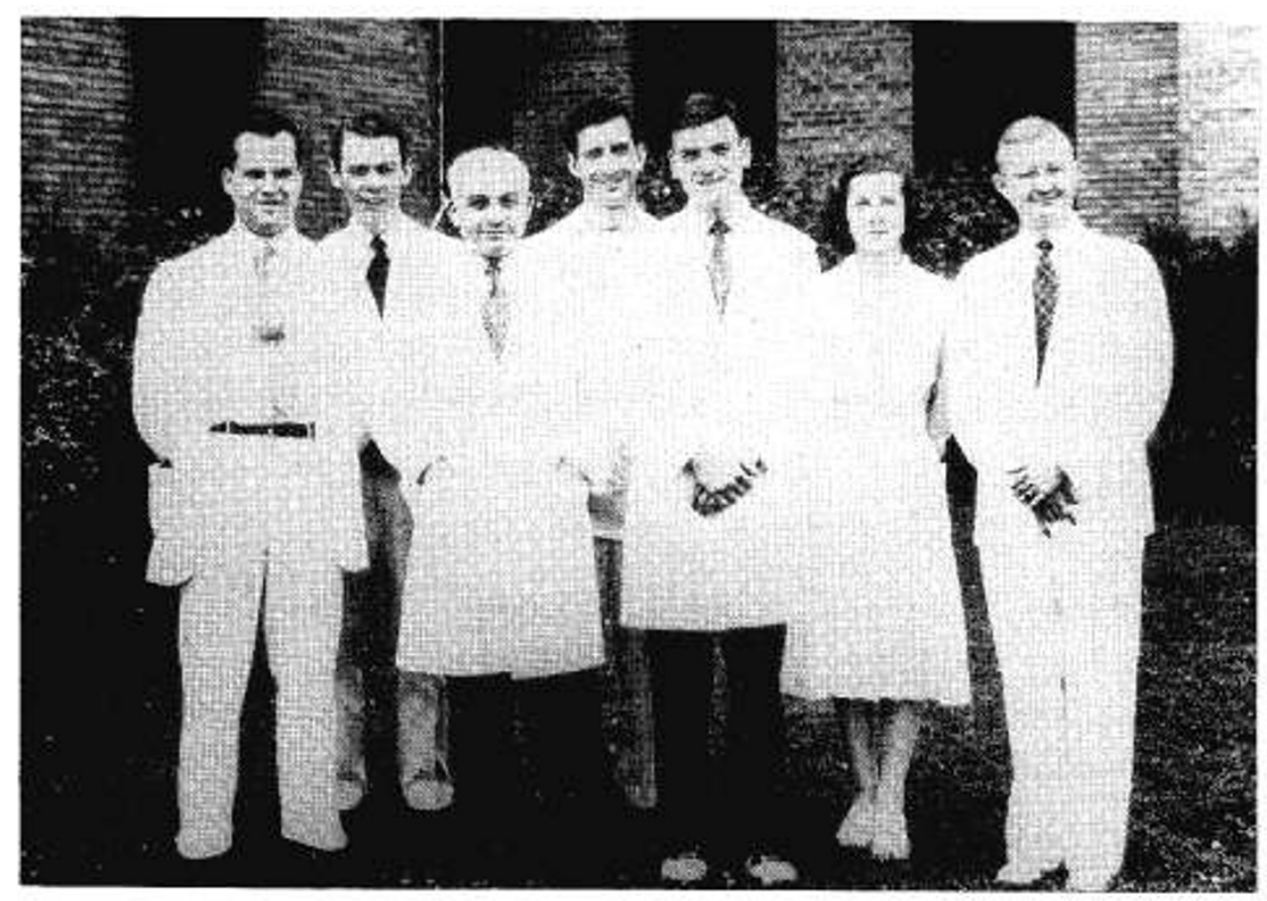

Fig. 7. Baltimore City Hospitals, Pediatric Staff, 1950. 


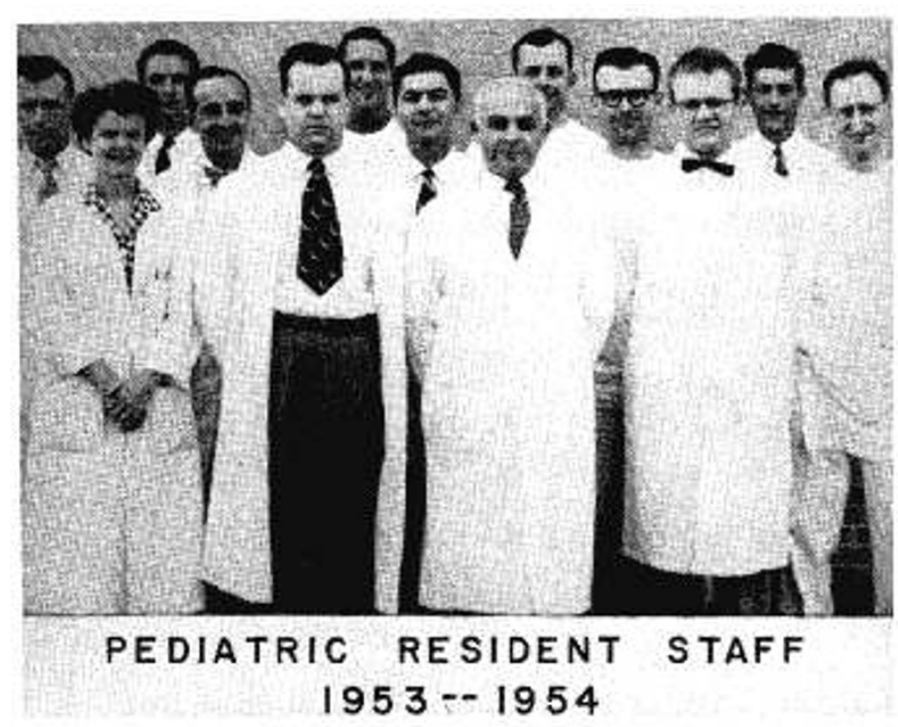

Fig. 8. Baltimore City Hospitals, 1953-54.

intestine, and on various other aspects of calcium metabolism. In 1961 this work has recognized by Harold receiving the Borden Award of the American Academy of Pediatrics. Together, our medalists continued their fundamental work until about 1978 . Then they completed as yet unfinished manuscripts, and they contributed a classic book on the pediatric aspects of calcium and phosphorous metabolism:

Along the way they were influential in shaping the careers of pediatric clinicians from the residency program and academicians through fellowships in their laboratory. I will make special mention of those now in academic medicine, Julian J. Chisolm, George G. Graham, Fima Lifshitz, Arthur Grollman, and J. Perheentupa, all of whom have gone on to multiple achievements in scholarly work.

A generation of clinicians with great knowledge, bedside skills, and dedication learned from discussions and example have all served children well, particularly in Baltimore, but over the world as well. The example set was a difficult one to emulate, but no one was to do less than his/her best. If that was the case then even if failure followed, you were received with patience and renewed encouragement. Not doing ones best received condemnation and few ever made this error a second time. In the clinical research area, in the days long before there were Institutional Review Boards, one wasn't needed. The ethics and humaneness of each project had to meet a standard higher than is true for many an approved project today.

At the Baltimore City Hospitals, Harold assumed the profes- sional leadership early on and held it for many years dragging that institution kicking and screaming into the 20th century and eventually to a level of excellence not often seen in similar institutions. This meant working with administrators, civil servants, politicians, and community agencies, consuming much time but always for the benefit of children. Never was there confusion in distinguishing what was good for children from what was good for pediatricians. When they coincided, well and good, when not, only children were to be considered. The patience exhibited with children and with students, residents, and junior colleagues did not always extend to administrators, bureaucrats and politicians. What earlier observers had described as a youthful temper found outlet when important rational changes or programs were ignored or procrastinated unduly. An occasional surgeon also exhibited surprise after a stinging encounter over a patient with this otherwise somewhat shy, mild mannered man.

What of Helen's activities during these years? In addition to taking the major share of the early child rearing, running the laboratory, training technicians, and guiding fellows, she also became a member of the Board of trustees of a fine private school and in more recent years served on the admissions committee of the Johns Hopkins School of Medicine. She has received a distinghished alumna award from Goucher in recognition. She, (and Harold) have seen their boys, Stephen and Richard, mature to respected scientists, professors at Harvard and Yale, respectively. Ricky and his wife have twin daughters, grandchildren who delight our medalists.

A husband and wife thrown together not only with home and family but at the laboratory bench as well-how can it be done and simultaneously preserve a marriage? Not many couples could carry it off, but this pair did it in every way. What personal characteristics enabled them to succeed? Helen possesses great sensitivity, personal outgoing warmth, and social poise. She is one of those socially gifted people who can and does put all kinds of people instantly at ease. As an example of this, for many years she "presided" over a lunch table at Hopkins attended by junior faculty, fellows and residents listening empathetically to their tribulations and burdens. Clearly she brought these traits to her family as well. Harold, less outgoing, though also very sensitive to people, invariably responds with helpful sympathy to anyone in need. He possesses a blend of integrity, great intelligence and kindness, a triad of traits that has made him a great clinician, teacher, colleague and friend. The blended personal qualities of our first couple have given them a family life to equal or perhaps even excel their magnificent professional contributions.

As we honor them, indeed we also honor ourselves. They have carried the torch of American Pediatrics from those following the founding generation to our contemporary one. They have given us an impressive, even awesome example and challenge. 